\title{
Use of a smart natural material to remove zinc and cadmium from water
}

\begin{abstract}
The use of available waste materials as adsorbents of heavy metals from industrial wastewaters was investigated. Metallic ions of $\mathrm{Zn}$ and $\mathrm{Cd}$ are some of the most difficult contaminants to remove from the aqueous streams in the environment. This paper proposes a novel process for the removal of these elements from water using smart dry sludge. The technique uses solid sludge supplied by the water treatment plant of the city of Al-Ain, located in the Emirate of Abu-Dhabi of United Arab Emirates. The proposed technique could be used at low cost and with great efficiency in the purification of drinking water. The method used in this research was developed in order to develop a comprehensive technique that reduces heavy metal concentration to an acceptable level. The SEM was used to explore the surface of the sludge to ensure the availability pores that may add additional advantages for retention of heavy metals. The proposed method shows great efficiency and the end concentrations of the product reached an acceptable level.
\end{abstract}

Keywords: environment, ZN and CD, adsorbents, waste materials, heavy metals, cadmium, zinc, toxicological effects, human health, drinking-water, cancer in the skin, lung
Volume 2 Issue I - 2018

\author{
Omar Chaalal,' Hameed Muhamad,' Md \\ Monwar Hossain ${ }^{2}$ \\ 'Department of Chemical Engineering,Abu Dhabi University, \\ UAE \\ ${ }^{2}$ Department of Chemical Engineering, UAE University, UAE
}

Correspondence: Omar Chaalal, Department of Chemical Engineering, Abu Dhabi University, UAE, Tel 0097I 555423254, Email omar.chaalal@adu.ac.ae

Received: December 27, 2017| Published: January II, 2018

\section{Introduction}

Heavy metals, such as, cadmium, zinc, Strontium and Arsenic have different chemical and physical properties. Also, each metal has its specific toxicological effects; in general, the contamination caused by heavy metals can have different effects in a human health. It is worth to summarize the effect of each element on human health. Scientific literature shows that cadmium affects the cardiovascular system in several ways. Much of the literature supports a role for $\mathrm{Cd}$ in inducing hypertension ${ }^{1}$ and diabetes, ${ }^{2}$ with apparent direct toxic impact on gene transcription in the vascular endothelium. ${ }^{3}$ The effect of Zinc is different since this element has known beneficial and necessary effects on a human body. Even though Zinc is vital to many bodily functions, at higher concentrations, toxic effects take control. At higher concentrations, zinc can become potentially serious if the dose exceeds $450 \mathrm{mg}$ a day. ${ }^{4}$ Strontium is not highly toxic but strontium and calcium have similar chemistry therefore strontium can accumulate in bone and affect bone formation at sufficiently high doses. ${ }^{5}$ Arsenic is introduced into water through the dissolution of rocks, minerals and ores, from industrial effluents, including mining wastes, and via atmospheric deposition. ${ }^{6}$ The predominant form is arsenic (III. Long-term exposure to arsenic in drinking-water is causally related to increased risks of cancer in the skin, lungs, bladder and kidney, as well as other skin changes such as hyperkeratosis and pigmentation hanges). ${ }^{7,8}$

Thus for many years chemical engineers have been attracted to new techniques of waste treatment requiring less energy and less pollutant in order to reduce the contents of heavy metals in the environment. One of these techniques is the use of natural absorbents to degrade or detoxify hazardous waste. The technique is now recognized as not only as viable alternative but a desirable alternative and/or additional to the traditional remediation technologies. ${ }^{9}$ Immobilized bacterial cell have also been proposed for the treatment of liquid wastes containing heavy metals ions. Khoshmanesh and co-workers used green micro algae in the removal of heavy metals from polluted waters. ${ }^{10,11}$ Furthermore, Skaguchi have indicated the importance of algae and their role in the bioremediation of toxic metals. In fact this bio concentration can pose a dangerous threat to higher organisms. ${ }^{12}$ The same technique was used by Chaalal and co-workers as part of a process that was proposed to remove traces of radioactive elements found in water. ${ }^{13,14}$ Modeling of adsorption of heavy metals onto natural material has attracted many researchers. In 2015, Chaalal and co-workers have developed a comprehensive approach for modeling sorption of lead and cobalt ions through fish scales as an adsorbent. ${ }^{15}$ A detailed phenomenological mathematical modeling of heavy metal biosorption in fixed-bed columns was published in 2016 by Suzaki and co-workers. ${ }^{16}$ It is believed that zinc and cadmium adsorption onto sludge developed in this paper follows the diffusion model described by Maria. ${ }^{17}$ The same assumptions can be made:

i. The aqueous phase is an isothermal and incompressible fluid containing manganese at a known initial concentration and $\mathrm{pH}$;

ii. The porous adsorbent particles of bone char are perfectly spherical, containing reacting sites that are homogeneously distributed within them;

iii. The reaction of manganese in the bone char particles is governed by a chemisorption mechanism; ${ }^{18}$

iv. equilibrium is described by the Langmuir adsorption isotherm; ${ }^{18}$

v. The system is perfectly mixed, so the external mass transfer process occurs solely in a thin boundary layer surrounding the particles, and

vi. The $\mathrm{pH}$ of the external. The numerical solution of the model is beyond consideration in this paper.

\section{Apparatus and materials}

Inductive Coupled Plasma-Atomic Emission Spectrometer. 
Inductively coupled plasma-atomic emission spectrometry (ICPAES) was used to determine metals in solution. This method is a consolidation of existing methods for water, wastewater, and solid wastes. The ICP-3000 was supplied by Skyray Instrument Co. Dried sludge mass was provided by the department of Sanitary drainage, from Zakher sewage treatment plant. This is a by-product of the biological treatment process of wastewater. The balance used with capability to measure to $0.1 \mathrm{mg}$, for use in weighing solids, for preparing standards, and for determining dissolved solids.

\section{Glassware}

All glassware was soaked in $0.1 \mathrm{M} \mathrm{HCl}$ overnight. GFC were obtained from Whatman Co.

\section{Reference sample material}

The reference material was sewage sludge of domestic origin, BCR No.144 that was obtained from the Community Bureau of Reference Materials, Belgium.

\section{Chemicals}

Spectrosol $\mathrm{Zn}$, Cd standard solution $(1000 \mathrm{mg} / \mathrm{l})$ was obtained from Sigma. Serial and dilution was made using deionized water Hydrochloric acid (36\%) and $\mathrm{NaOH}(40 \%)$ used were of analytical grade, obtained from Sigma.

\section{Experimental procedure}

Preparation of sludge: Three grams of sludge was dried in an oven at $60{ }^{\circ} \mathrm{C}$ for 5 hours. The sludge was washed with $50 \mathrm{ml}$ of $0.1 \mathrm{M}$ $\mathrm{HCl}$ several times to remove the initially adsorbed metals until the washings were free from any metals and this was utilized for this study.

Metal ion solutions: Different metal ions concentration were prepared by serial dilution covering the range of $5-100 \mathrm{mg} / \mathrm{I}$ using deionized water and $\mathrm{pH}$ was adjusted using $\mathrm{NaOH}$ of $\mathrm{HC} 1$. 0.1gms of sludge was mixed with $250 \mathrm{ml}$ of different concentrations of the metal solutions. The solutions were shaken overnight in a bottle shaker. Then the mixture was filtered through a glass fiber circle and the filtrate was analyzed for residual metal content.

\section{Results and discussion}

Electron image analyzer was used to investigate the pore size and the pore distribution on the surface of the natural materials used. These pores play an important role in metal adsorption of zinc and cadmium. Fig 1 shows the SEM image of the surface of the activated sludge before treatment. Figures 2 and 3 show the comparison of activated sludge treated surface and activated carbon surface. It was noticed that the pore distribution and their sizes were different as compared to the pores that appeared on the activated carbon surface. So metal adsorbed on the pores surface was disputed and adsorption of heavy metals by microorganisms was the only possible process. So this phenomenon was utilized in removal of $\mathrm{Zn}$ and $\mathrm{Cd}$ from wastewater using acid washed sewage sludge (Figures 1-3).

\section{Adsorption isotherms}

Langmuir adsorption theory assumes that the adsorption sites are equivalent and that the binding of a particular species is independent of the occupied binding sites. ${ }^{19}$ Consequently the binding reaction may be represented as a single equilibrium expression with the transposed
Langmuir isotherm expressed as follows:

$$
\frac{1}{q}=\frac{k}{q_{m}} * \frac{1}{c}+\frac{1}{q_{m}}
$$

Where "q" is the milligram of metal adsorbed per gram of sludge, $\mathrm{k}$ is the equilibrium constant, $\mathrm{c}$ is the equilibrium concentration $\left(\mathrm{mg} \mathrm{L}^{-1}\right)$ and $\mathrm{q}_{\mathrm{m}}$ is the quality in the milligram of metal adsorbed at saturation of a single adsorption site. A plot of $1 / \mathrm{q}$ versus $1 / \mathrm{c}$ should yield a straight line with a slope of $\mathrm{k} / \mathrm{q}_{\mathrm{m}}$ and intercept of $1 / \mathrm{q}_{\mathrm{m}}$.

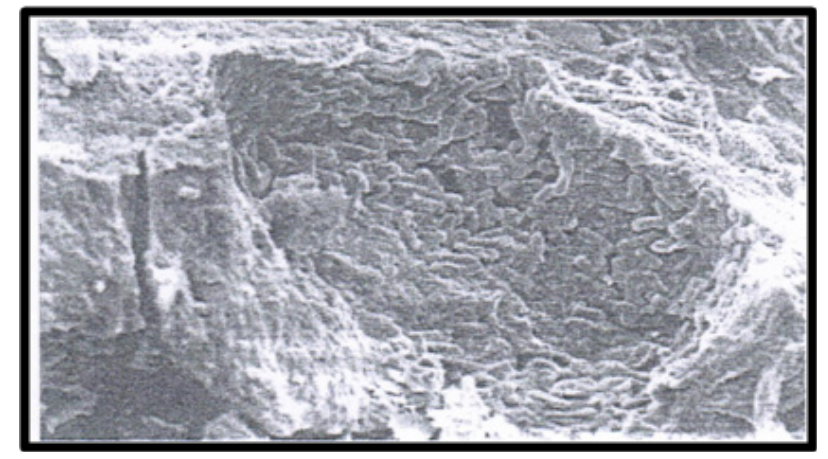

Figure I SEM image of sludge before treatment.

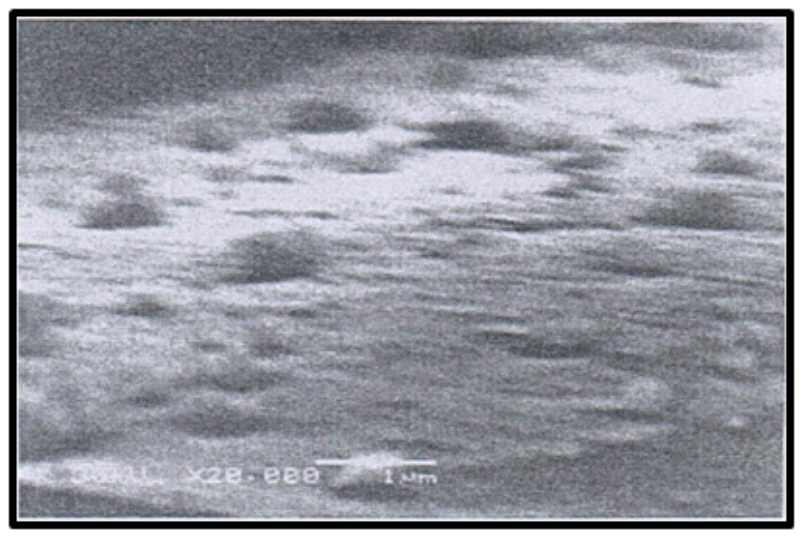

Figure 2 Surface of Activated Carbon.

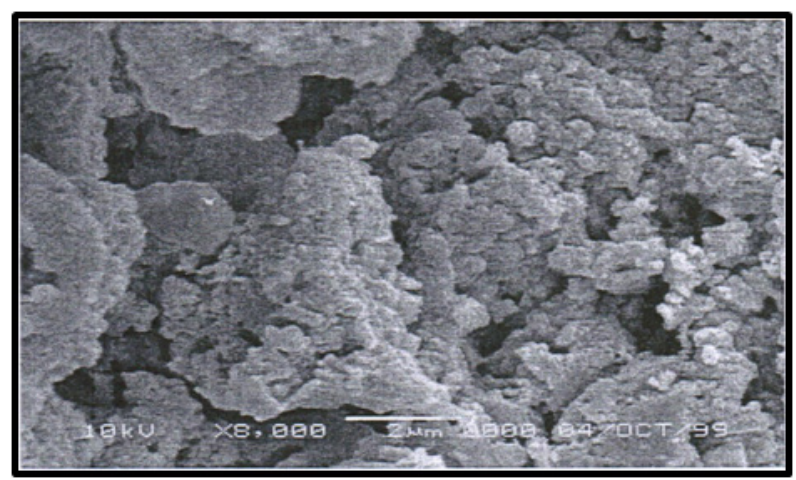

Figure 3 Surface of Sludge after treatment.

The adsorption of zinc and cadmium (Figure 4) (Figure 5), the study of these figures showed that the sludge displayed slightly similar adsorption behavior for all the metals respect of Langmuir isotherm shapes. For all elements the isotherm increase as the equilibrium concentration increases. It was observed that at lower concentrations 
(0-5) the uptake of $\mathrm{Cd}$ is much higher than that exhibited with $\mathrm{Zn}$. Furthermore, the study indicates that in case of $\mathrm{Cd}$ the species that are first adsorbed facilitates the adsorption of additional species. However, one can notice also that even at higher concentrations the uptake for $\mathrm{Cd}$ is much significant than in the case of $\mathrm{Zn}$. These results can be explained by the adsorption behavior of the isotherm and it is evident that $\mathrm{Cd}$ uptake took place at lower concentration and $\mathrm{Zn}$ uptake by sludge is retained at approximately higher concentration. This phenomenon indicates that the binding sites are different and it is confirmed by the plot of Langmuir isotherms. The plot of $1 / \mathrm{q}$ as a function $1 / \mathrm{C}_{\mathrm{f}}$ represented in (Figure 6) (Figure 7) exhibits a straight line in case of $\mathrm{Zn}$ and that indicates only one binding site is involved in metal chelation whereas it is very clear in the case of $\mathrm{Cd}$ that the same plot showed a semi curve line at lower concentration. The behavior of the plot at lower concentrations confirms that some other factors are operating and more than one binding sites are involved in metal retention. It appears also that those sites are quite different from those in the case of $\mathrm{Zn}$ and they are responsible for the additional quantity of uptake in case of $\mathrm{Cd}$. Therefore the uptake of $\mathrm{Cd}$ is higher than the $\mathrm{Zn}$ uptake at specific concentrations.

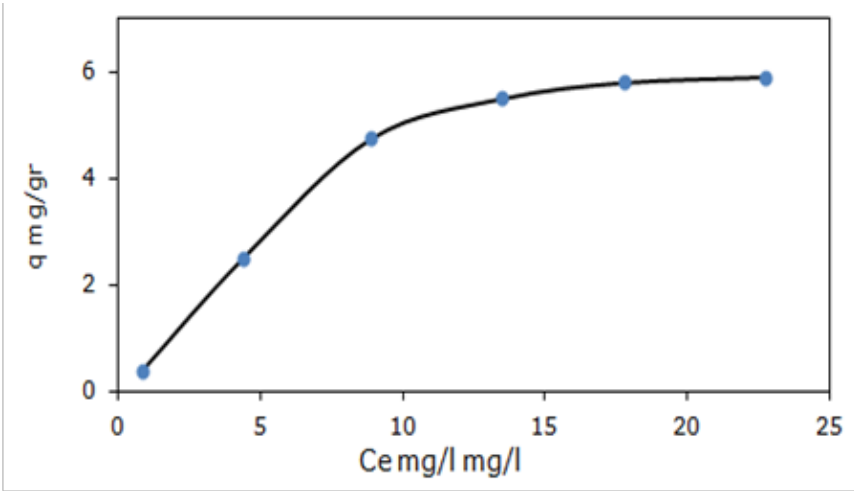

Figure 4 Adsorption Isotherm of $\mathrm{Zinc}\left(\mathrm{Zn}^{++}\right)$by sludge.

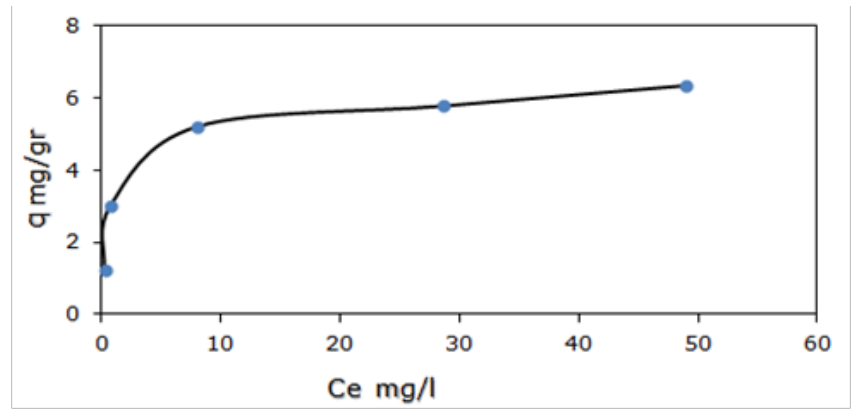

Figure $\mathbf{5}$ Adsorption Isotherm of Cadmium $\left(\mathrm{Cd}^{++}\right)$by sludge.

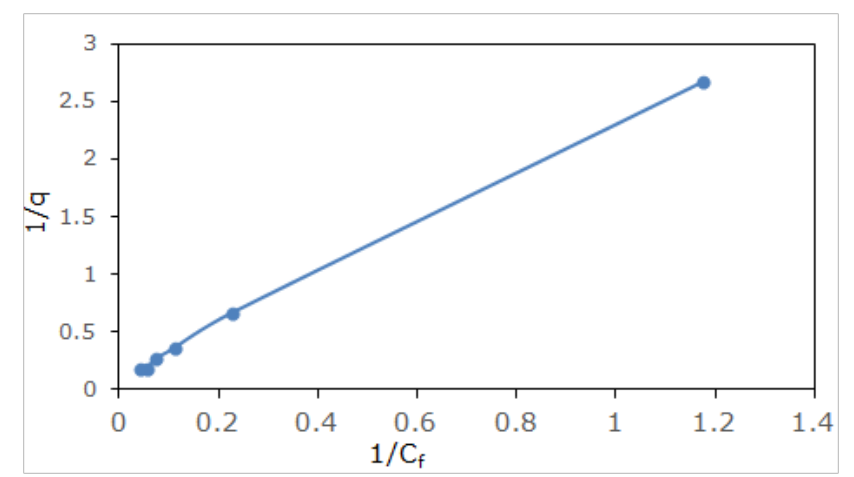

Figure 6 Langmuir Isotherm for Zinc $\left(\mathrm{Zn}^{++}\right)$.

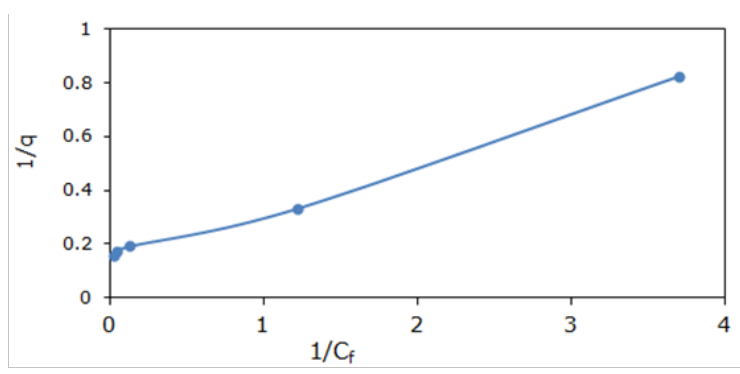

Figure 7 Langmuir Isotherm for Cadmium $\left(\mathrm{Cd}^{++}\right)$.

\section{Conclusion}

Toxicity of heavy metals poses a serious health hazard and there is a need to control its emissions into the environment. Bio-sorption can become an effective technique for remediation of heavy metal contamination, namely with $\mathrm{Zn}$ and $\mathrm{Cd}$. The Experimental results demonstrate that activated sludge is capable of removing heavy metals like $\mathrm{Cd}$ and $\mathrm{Zn}$ from wastewater.

\section{Acknowledgements}

None.

\section{Conflict of interest}

The authors declare that there is no conflict of interest.

\section{References}

1. Gallagher CM, Meliker JR. Blood and urine cadmium, blood pressure, and hypertension: a systematic review and meta-analysis. Environmental Health Perspectives. 2010;118(12):1676-1684.

2. Edwards JR, Prozialeck WC. Cadmium, diabetes and chronic kidney disease. Toxicol Appl Pharmacol. 2009;238(3):289-293.

3. Bernhard D, Rossmann A, Henderson B, et al. Increased serum cadmium and strontium levels in young smokers: effects on arterial endothelial cell gene transcription. Arteriosclerosis Thrombosis and Vascular Biology. 2006;26(4):833-838.

4. Guido Rychen, Gabriele Aquilina, Giovanna Azimonti, et al. Safety and efficacy of zinc chelate of methionine sulfate for all animal species. EFSA Journal Volume. 2017;15(6):e04859.

5. Mustafiz S, Basu A, Islam MR, et al. A Novel Method for Heavy Metal Removal. Journal Energy Sources. 2002;24(11):1.

6. Hindmarsh JT, McCurdy RF. Clinical and environmental aspects of arsenic toxicity. Crit Rev Clin Lab Sci. 1986;23(4):315-347.

7. Paramita Mandal. An insight of environmental contamination of arsenic on animal health. Emerging Contaminants. 2017. p. 3.

8. Kadirvel R, Sundaram K, Mani S, et al. Supplementation of ascorbic acid and $\alpha$-tocopherol prevents arsenic-induced protein oxidation and DNA damage induced by arsenic in rats. Hum Exp Toxicol. 2007;26(12):939946.

9. John Fawell, Mark J Nieuwenhuijsen. Contaminants in drinking water: Environmental pollution and health. British Medical Bulletin. 2003;68(1):199-208

10. Ting YP, Lawson F, Prince IG. Uptake of cadmium and zinc by the alga Chlorella vulgaris: Part 1. Individual ion species Biotech Bioeng. 1989;34(1989):990-999.

11. Khoshmanesh A, Lawson F, Prince IG. Cadmium uptake by unicellular green microalgae. Chem Eng J. 1995;(62):81-88. 
12. Khoshmanesh A, Lawson F, Prince IG. Cell surface area as major parameter in the uptake of cadmium by unicellular green microalgae. Chem Eng J. 1997;(65):13-19.

13. Maeda S, Skaguchi T. Accumulation and detoxification of toxic metal elements by algae, In: Akatshuka, editor. Introduction to Applied Physiology. Academic Publishing The Hague. 1990. p. 137-149.

14. Chaalal O, Islam MR. Integrated management of radioactive strontium contamination in aqueous stream systems. Journal of environmental management. 2001;61(1):51-59.

15. Chaalal, Zekri AY, Soliman AM. A novel technique for the removal of strontium from water using thermophilic bacteria in a membrane reactor. Journal of Industrial and Engineering Chemistry. 2015;21:822-827.

16. Basu A, Mustafiz S, Islam MR, et al. A comprehensive approach for modeling sorption of lead and cobalt ions through fish scales as an adsorbent. Chemical Engineering Communications. 2006;193(5):580605
17. Pedro Yahico Ramos Suzaki, Mauricio Tombini Munaro, Carina Contini Triques, et al. Phenomenological mathematical modeling of heavy metal biosorption in fixed-bed columns. Chemical Engineering Journal. 2017;326:389-400

18. Maria ME, Mansur MB. Mathematical modeling of batch adsorption of manganese onto bone char. Brazilian Journal of Chemical Engineering. 2016;33(2):373-382.

19. Crist H, Karl, Oberholser, et al. Nature of bonding between metallic ions and algal cell walls. Ray Ming Nguyen Environ Sci Technol. 1981;15(10):1212-1217. 